\title{
Russian digital education landscape during the current pandemic: is the impact felt?
}

\author{
Elena Soltovets $^{1}$, Oksana Chigisheva ${ }^{1,2}$, Denis Dubover $^{3, *}$, and Anna Dmitrova ${ }^{1}$ \\ ${ }^{1}$ Southern Federal University, 105/42, Bolshaya Sadovaya str., Rostov-on-Don, 344006, Russia. \\ ${ }^{2}$ Institute for Strategy of Education Development of the Russian Academy of Education, 1, \\ Zhukovskogo str., Moscow, 105062, Russia. \\ ${ }^{3}$ Don State Technical University, 1, Gagarin Square, Rostov-on-Don, 344003, Russia.
}

\begin{abstract}
The paper aims at tracing rapid changes in Russian digital education landscape having been shaken by the pandemic of 2020. To this end the study deals with the bulk of publications contributed by the Russian language authors to the Russian Science Citation Index (RSCI) Database as the fullest national research representation source, which includes the most influential research journals in the educational domain. The main research question that potentiated this study was weather the "shock digitisation" faced by many teaching practitioners has been problematized in recent Russian educational discourse. We rely upon the proposition that quick and dramatic shifts can impede adequate scientific reconceptualization of digitisation phenomenon as practical needs stand first in the priority. To test the proposition, the method of content analysis targeting the titles and abstracts of the papers included into Russian Science Citation Index database has been used. Findings demonstrated insignificant increase in the number of pandemic related publications on education digitisation. The data obtained suggests that the influence of the pandemic is little observed in the issues addressed by the latest publications in the Russian educational journals. The study can be of certain prognostic value for international comparative educationalists and policy makers.
\end{abstract}

\section{Introduction}

At the end of the last academic year, Russian education system faced new challenges due to the difficult epidemiological situation and restrictive measures introduced in the country and the whole world in connection with the spread of COVID-19. According to the Decree of the President of the Russian Federation dated March 25, 2020 No. 206 On the announcement of non-working days in the Russian Federation from March 30, 2020 to April 3, 2020 [1], a series of restrictions entered into force to ensure the sanitary and epidemiological well-being of the population in the constituent entities of the Russian Federation due to the spread of coronavirus infection.

\footnotetext{
* Corresponding author: denisdubover@gmail.com
} 
The restrictions, extended several times (April, 4-30; May, 1-11), were in effect until May 11, and only later the country began its gradual exit from quarantine as there was a registered decrease in the number of infected with SARS-CoV-2. The regions were granted rights to introduce additional restrictions to further prevent the virus spread or to initiate step-by-step elimination of restrictive measures in accordance with the orders and regulations on the federal level. Along with self-isolation and social distancing, one of the containment measures against the spread of infection was the closure of educational institutions, including supplementary vocational education institutions throughout Russia and the forced transition to distance learning [2], which required accelerated adaptation to the new digital reality of all participants of the educational process.

It is worth noting that before the landslide forced transition to online learning in the Russian Federation, a number of initiatives had already been planned. This fact significantly promoted formation of the basis for intensifying digitisation processes in education in the nearest future. So, within the framework of one of the ten federal projects and programs of the largest National project "Education" (2019-2024) "Digital educational environment", it was planned to "create conditions for the introduction by 2024 of modern and safe digital educational environment that provides value formation for selfdevelopment and self-education among students of educational institutions of all types and levels, by updating the information and communication infrastructure, training, creating federal digital platforms" [3, p. 2].

In 2017, the implementation of the strategically important concept of the University 20.35 was launched at the federal level, which is scheduled to be completed in 2035. It is a digital educational platform of the world format and level, the purpose of which is to form "the educational system of a new type, capable of responding to the challenges of the new technological order, influencing the speed, quality and scale of changes" [4, p. 7].

In other words, the platform should ensure the professional development of a person in the digital economy, using technologies and tools of digital education and be based on the main postulates stated in the National Technological Initiative (NTI). The project is already underway in such areas as AeroNet, AutoNet, EnergyNet, SafeNet, HealthNet, EnergyNet, FashionNet, MariNet and the circle movement [5].

These strategically important objectives were planned to be achieved in stages, which would allow gradual adaptation to digital innovations. However, the pandemic has made its own adjustments to this process, and "shock" digitisation has become a challenge not only for the entire system of domestic education, but also for all teacher forced to restructure his/her professional activities significantly in order to meet the new requirements of online educational environment. According to the survey of Russian teachers conducted by the Analytical Center of the National Agency for Financial Research and published in July 2020, the following issues were identified as problems hindering effective transition to online format and clearly manifested in the education system during the pandemic $(\%$ of teachers who noted that they need help with this):

1. problems with technical equipment - 31\%;2. - methodological assistance is needed, there is not enough understanding of the resources available and more convenient to use $24 \%$; 3. technical knowledge, computer skills - 21\%; 4. low quality of open access materials, fragmented resources, lack of a single platform - 12\%; 5. need in responsive technical support, instruction and advice from technical specialists - 9\%; 6. need in reduction of working load, not enough time - 7\%; 7. freezing of portals, especially of electronic journal, electronic materials - $6 \%$ [6].

Obviously, the issues associated with the existing misbalance in the field of digital literacy come to the fore, which requires school and university teachers to expand knowledge in the field of digital education, master the skills necessary for work in digital educational environments and on digital platforms, increase appropriate methodological 
resource and "best practices", which will ultimately help to improve their digital functionality. In our opinion, this will help achieve the national goal "Digital transformation", in terms of bringing Russian education to the "digital maturity", indicated in the recent Decree "On the national development goals of the Russian Federation for the period up to 2030" [7], signed by the President of the Russian Federation on July 21, 2020.

\section{Literature Review}

Digitisation of education is a necessary requirement for the educational process to function smoothly in modern conditions. Various aspects highlighting the impact of digital technologies on the educational process have been reflected in the publications by many Russian researchers.

Digitisation has affected all educational levels. But most of the publications by Russian scholars are studies of the digital transformation occurring in the university environment. Thus, digitisation is seen as one of the challenges [8] or a systemic change in higher education [9]. Other researchers analyze possible problems and risks of implementing digital technologies into the educational process, that are mainly caused by insufficient funding, poor technical equipment and lack of methodological support of teachers [10], [11].

Rethinking of the teacher's role in the digital educational environment was reflected in the publications of such Russian researchers as Dyakova E.A. and Sechkareva G.G. [12], Nikulina T.V. and Starichenko E.B. [13].

Another direction in the field of studying digitisation of education is associated with the fact that ubiquitous equipping of workplaces with digital technologies transforms the requirements for trained personnel, which, in turn, affects the updating of the educational programs ' content and the list of learning outcomes. In this regard, such concepts as information competence [14], digital competence [15], digital literacy [16], digital skills [17] are introduced into the scientific discourse. It is also necessary to update the requirements for the professional qualifications of researchers in accordance with the challenges of digitisation [18].

Particular attention of researchers was paid to safe and psychologically comfortable digital educational environment, especially at the school level [19], as well as the use of information technology for education of disabled children [20] and for education of senior citizens [21].

Regulatory documents analysis characterizing the state policy of Russia in the field of education digitisation is made in the works of Dneprovskaya N.V. [22] and Savina A.G. [23].

Some Russian scholars [24], [25], [26] studied foreign experience in order to identify effective practices for introducing digital technologies into the educational process. While others [27], [28], [29] presented successful examples of digitisation in domestic educational institutions. As a rule, these publications concerned a review of digital tools used in the educational process, or descriptions of disciplines that develop skills necessary for students and teachers to work with digital technologies.

The issues of changing didactics in the context of digitisation are addressed in the publications of Robert I.V. [30], Blinov V.I. [31], Tarkhanova I. Yu. [32]. These scholars have made significant contributions to the description of the didactic principles for the digital age.

However, the study of the didactic layer in the Russian scientific discourse is rather fragmentary, on the whole, and is not typical for most researchers dealing with digitisation of education. In this regard, despite the fact that Russian researchers analyze various areas of educational digitisation, there are still gaps in identifying the didactic potential of using 
digital technologies in education, as well as in reconceptualising theoretical positions on the digital educational environment and its development, especially under the influence of new global challenges (for example, Corona crisis of 2020).

\section{Research Focus and Methods}

In the course of the research, we mainly focused on the analysis and rethinking the situation in the Russian education system against the background of the pandemic and introduction of restrictive measures that entailed a complete transfer of the educational process into the digital environment. For this purpose, we turned to the analysis of secondary data presented in the Internet publications, interviews and surveys on the issue under study. This allowed to provide logical and persuasive author's interpretation of the events or, in the terminology of Tertychny A.A., "displayed reality" [33, p. 48], using factual and evaluative models of argumentation when formulating and substantiating generalizing theses and evaluative judgments.

At this stage, the need to transfer the consideration of the current situation into the theoretical dimension became obvious. Thus, it required testing the assumption that perhaps the forced transition to distance learning due to the spread of COVID-19 contributed more to debating the unforeseen challenges accompanying it, rather than to a detailed study of transformation processes in didactic and methodical principles used for digital education purposes and the emergence of new thematic lines, problems and solutions (technological, methodical, instrumental, organizational) in this area.

To solve this research problem, we used content analysis, as well as reductive research methods - analogy, comparison, categorization. The RSCI database became the source of the study, the word "digitisation" was chosen as a working unit of analysis. The analyzed period covered 2017-2020 years, the total number of publications for this time line was considered as $100 \%$. The search was carried out in the section "Public education and pedagogy" in the automatic regime.

The data obtained within content analysis research was presented and interpreted depending on the chronological, geographical and thematic features. We admit that missing data or incomplete data in the Russian Science Citation Index (RSCI) could, to a certain extent, affect the results in some positions, because "incomplete data may be overlooked or neglected" [34, p. 469]. This fact imposes some limitations during the analysis and insignificantly reduces the volume of the evidence when formulating the conclusions.

\section{Results and Discussion}

March of 2020 that set the ball of pandemic-prevention measures in Russian education rolling catalyzed a number of transformations that had been looming for years before. In fact, Russian education was forced to make the giant leap for digital learning environment it had been approaching taking small steps. Arguably, those steps tend to have been too small. Thus, a plunge into the reality of entirely digital academic communication naturally brought about some confusion and perplexity. Taking into account that no schedules of Covid-19-related moves were pre-emptively announced neither by local nor by the state education authorities, it comes as no surprise that they had been rather intuitively anticipated but never expected.

By the middle of March, when the growing number of the infected started to pose a threat due to the disease's high contagiousness, most educational establishments issued decrees initiating a transfer of all teaching and academic practices online. They were followed by series of the President's Decrees on non-working days. Together these legal 
acts formed some kind of "gray area" which allowed certain maneuvering time and space for teaching staff and administrative management in education. Within several weeks, or worse, a week, students-teachers interaction was to be made distant with any hardware and software resources available. To some extent, the situation was a challenge for both teachers' ingenuity and the learners'/parents' cooperativity. A wide range of digital media was being operationalized. Among the most popular were Russian educational online platforms, instant messengers, and video conference services. Conventional digital communication was significantly broadened to include all types of social networking, which used to be in a certain sense disregarded before due to its "entertaining and distractive" character. Although some tertiary institutions deployed a network of semifinished educational services, most employees found themselves in a "sink-or-swim" position, feeling swept by the tidal wave of technical issues and digital teaching products on offer. This can possibly account for the wide-spread feeling of being at sea, carried away with the torrent of current events, reported by the survey participants, alongside with the resentment towards having to rearrange the teaching routine [35]. Having to organize workstations at home and use mobile devices for unscheduled communication with the learners, teachers were struggling to squeeze personal life into non-stop work. The vast majority of survey respondents repeatedly complained about increased pressures and teaching load [36, p. 14], [37].

The acting rector of the Institute of Education Development in the Ivanovo Region in Russia Elena Yuferova states in her interview:

"Teachers are short of full value worktime being at home. They also need proper technological capacities, with the stable Internet connection above all. Lessons constructing requires comprehensive approach, when work is being coordinated at all levels, including teaching and administrative staff, regulatory authorities and organs providing feedback" [37].

Aleksandra Kuzmina, the head of the Centre of Online Education Development in Ural Federal University, claims that "teachers select best practices through trying things out, probing and experimenting" [38]. According to the Head of Tomsk State University Teachers' Retraining Centre, teachers gradually refuse from conventional format of lectures delivering.

"Online learning is absolutely specific chronotope and environment. An hour-long webinar is way too much to bear. The YouTube-shaped generation has problems with learning the information if it is just voiced from the screen. Now the Internet is swarming with videos and podcasts telling how to make the learning content enjoyable. Teachers are sharing experience how to produce content quickly and to present it to students in the best way. The number of synchronous teaching hours is falling, while asynchronous learning is on the rise. Asynchronous teaching is more time-consuming in terms of arrangements. Electronic environment is more demanding. It has to be carefully organized to be consistent and self-explanatory" [38].

At schools the shock was partly mitigated, however, by the fact that educational authorities tried to avoid imposing rigorously tight controls over the process [36, p. 10]. The institutions of higher education, on the contrary, were more eager to orchestrate centralized management in terms of methods, techniques, timescales, and products used. The major ones tended to rely on LMSs which had been occasionally experimented with before. Corporate strategies were developed and integrative solutions, where affordable, were introduced as mandatory. This fact was emphasized by the number of experts. The rector of Tambov State Technical University Mikhail Krasnjansky mentioned LMS among the functioning electronic resources of the University, along with the system of online testing AST. 
"The main information and communication objectives were accomplished via students', teachers' and partners' accounts. They make assignments accessible for students and help teachers to track the learners' progress. Students' profiles make learners' digital footprint visible. Zoom, Microsoft Teams, and social networks were used for staff-students communication" [39].

A similar situation is being described by Sergey Baklanov, the vice-rector of Ulyanovsk State University.

"All faculties switched into distant learning mode. We had been using e-learning environment. Its core is Moodle LMS integrated into $1 C$ University. The electronic resources include online lectures, courses, e-publications, seamless jump to e-library resources. Zoom and integrated testing systems are used for assessment" [39].

Leonid Koldunov, Associate Professor from Moscow Institute of Physics and Technology, tells about the changes accompanying transition to online environment.

"We started recording lectures that added to their quality. Seminars are now organized via Zoom” [40].

Using Moodle and MOOCs is also reported from Tomsk State University [38].

Neither of these two approaches has made the teaching staff's life easier. Digital "libertarians" faced multiple complaints from students and parents, who were struggling through multiple experiments of online learning directed by various teachers who tried to introduce discipline-specific targeted services. Moreover, they soon had to deal with difficulties of instrumental character, such as issues of accessibility, affordability, compatibility, usability etc. [36, p. 12]. Few teachers mentioned having sufficient videoconferencing equipment and broadband internet capacity. This problem was reported as particularly relevant for schools at the periphery [36, p. 12]. Such were the obstacles under the best scenario, where teachers were digitally skilled enough to play the roles of the new learning media missionaries. However, the very opposite was, in fact, more often the case. Being intimidated and frustrated with the infinite number of options requiring developed digital literacy, some educators shrank from leaving the comfort zone and resorted to well-explored services, not flexible enough to satisfy diverse teaching needs, thus leaving "digitally native" young learners disappointed and demotivated [41]. Hence, students (especially young learners) often feel fatigue and despair about an increase in home assignments and apparent shift towards learners' autonomy [41].

The "strong-hand" approach, meanwhile, generated its own set of stumbling blocks. Over-regulative and prescriptive management of academic communication resulted in complaints of the teaching staff about rigid technical and methodological frameworks, as well as excessive supervision. Bulging accountancy on teaching practices that used to be simple and conventional in face-to-face regime and exponential bureaucratization of academic procedures were mentioned among the disadvantages of the new educational reality. Instructors were also reporting on the needs of additional support with proper use of educational services and products adopted as mandatory [35]. Another issue of growing concern was professional retraining. On the one hand, respondents often mentioned a burning necessity of new skills and knowledge to adapt and integrate successfully into new digital educational environment. On the other hand, they found themselves buried under the avalanche of forcibly volunteered trainings and retraining sessions hurriedly organized by administrative offices nationwide and locally. The weeks of urged downtime opened the hectic spree of webinars, lectures, workshops, and development courses. The practice was extended further and stretched into the following months when scheduled academic workload was restored. While part of those trainings was felt as vital, its intensity and increasing time-consumption were often perceived as an additional burden disengaged from real-life demands. 
Thus, lively public discussion has revealed keen interest in the topic of challenges related to the hasty and not entirely well-timed dive into digital education. Multiple online debates and questionnaires issued since April 2020 to collect data allowing to monitor, if not control, ongoing transformation of education have evidenced certain concern on the matter. But to what extent this growing concern has been expressed in the research papers submitted by Russian practitioners within the period of Covid-induced digital transformation in education? To answer this question the largest Russian Science Citation Index database was analyzed to investigate the degree to which the topic has been explored. Lexical units of "digitisation" was chosen for content analysis in the scope of publications under the theme "Public education. Pedagogics". Surprisingly, no spike of publication activity, compared to the trends of previous years, has been found.

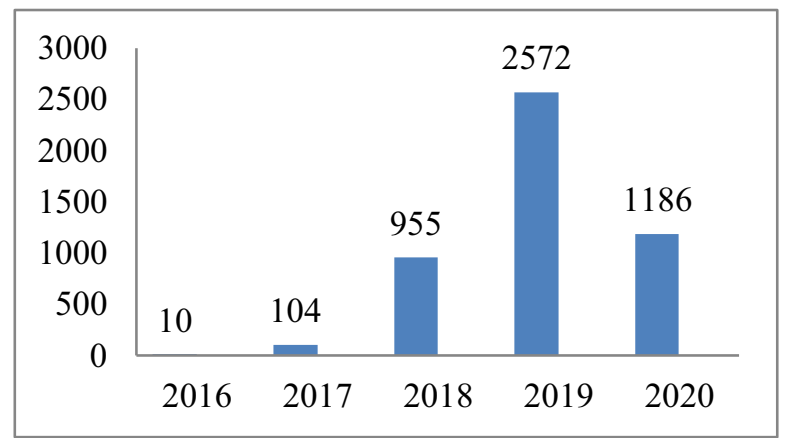

Fig. 1. Number of Publications within the Last 5 Years under the Topic "Public Education. Pedagogics." where "Digitisation" is Mentioned in the Title, Abstract or is Given as a Key Word, Source: the authors.

As it is seen from Figure 1, publication activity since the beginning of 2020 concurs with the trend. The subject of digitisation of education doesn't demonstrate any significant increase in the number of publications that might have been expected under the current circumstances. On the contrary, the following findings, shown in Figures 2 and 3, were quite predicable.

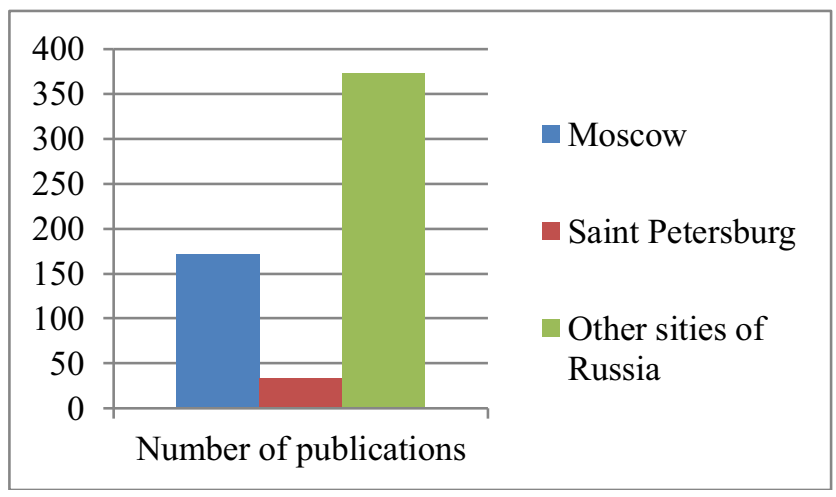

Fig. 2. Number of Education-related Publications with the Key Word "Digitisation" Authored by the Researchers in Moscow and Saint Petersburg Compared to the Number of Contributions from the Rest of the Cities in Russia (2020), Source: the authors.

Publications, contributed by the Moscow-affiliated authors outnumber those submitted from "the second capital of Russia" Saint Petersburg and account for almost half of all contributions made Russia-wide. The disparity is even more apparent in Figure 3, showing drastic disproportion in City/District figures correlation. 


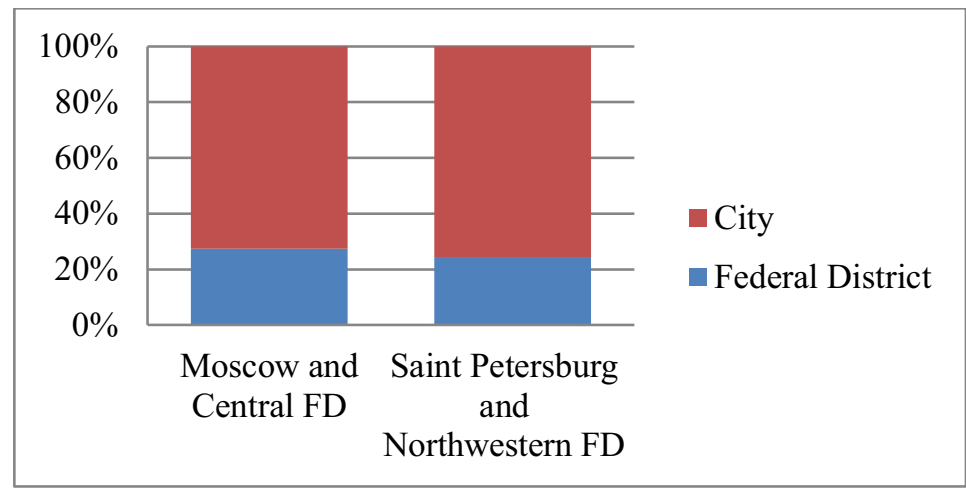

Fig. 3. Percentage of Education-related Contributions with the Key Word "Digitisation" made in Moscow and Saint Petersburg Compared to the Number of Contributions from the Rest of the Cities in the Federal Districts where Two Research "Capital Cities" are Geographically Located (2020), Source: the authors.

Thus, the capital cities provide the vast majority of contributions coming from the federal districts they are located in. The findings fit perfectly into the larger picture painted by teachers' surveys, showing significant imbalance in online teaching development and digital capacities in megalopolises and provinces of Russia [35]. The rest of the papers published in other Federal Districts show no striking results, as Figure 4 demonstrates.

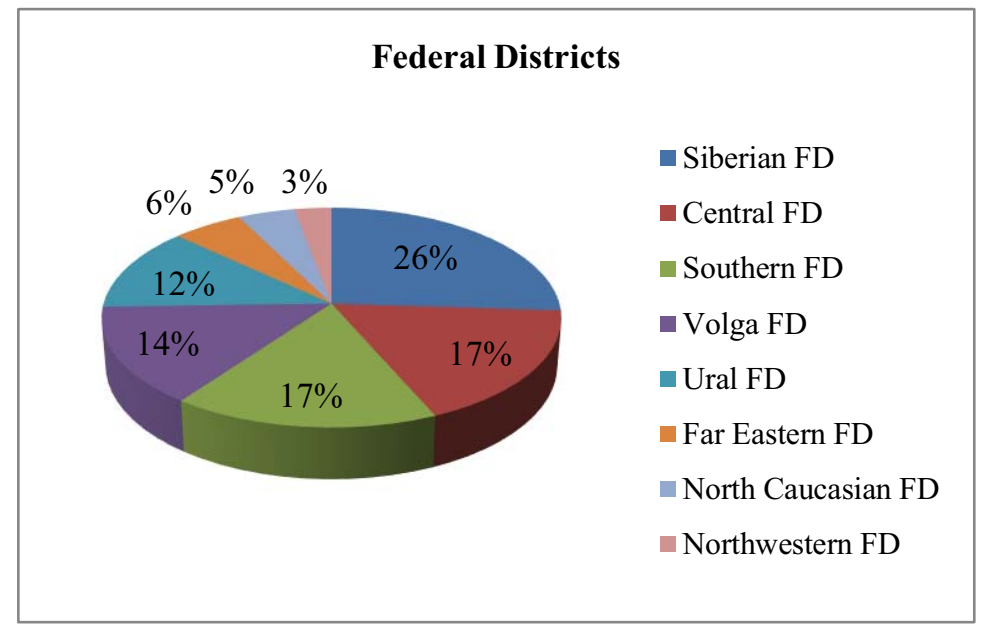

Fig. 4. Percentage of Publications Authored and Co-authored by the Contributors Affiliated with the Research and Education Institutions Located in Different Federal Districts of Russia, Source: the authors.

The data on Federal Districts' activity generally correlate with distribution of the research and scientific hubs in Russia (commonly based around the largest Federal Universities) and the population proportions. Further possible implications require in-depth analysis and lie beyond the objectives of this research paper.

As for the types of publications registered in the database, the pie chart in Figure 5 demonstrates two big segments accounting for the majority of contributions made in 2020 . 


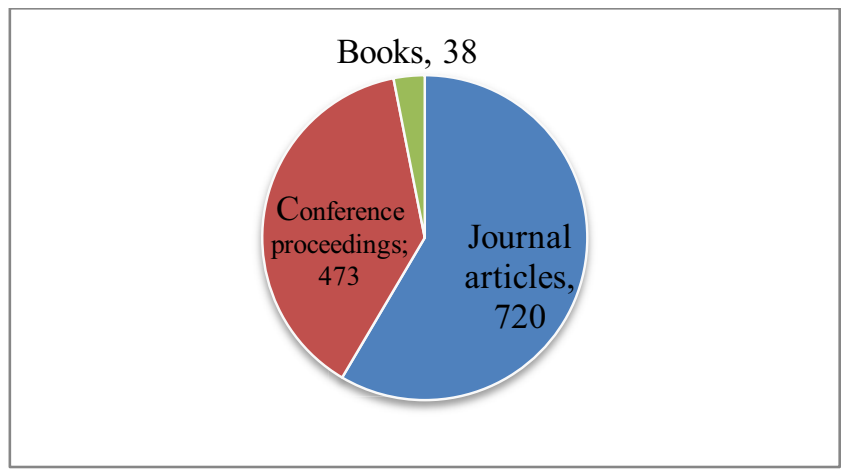

Fig. 5. Types of the Publications Made in 2020 were "Digitisation" is Mentioned in the Title, Abstract or is Given as a Key Word, Source: the authors.

Such picture can be explained by the time required for a paper to be issued. Thus, conference proceedings become the quickest publications to be indexed in the database, so the true scale might have to be assessed in retrospect.

As it was mentioned above, "Covid-19" and "pandemic" were given as key words in very few publications dealing with digitisation in education (see Figure 6).

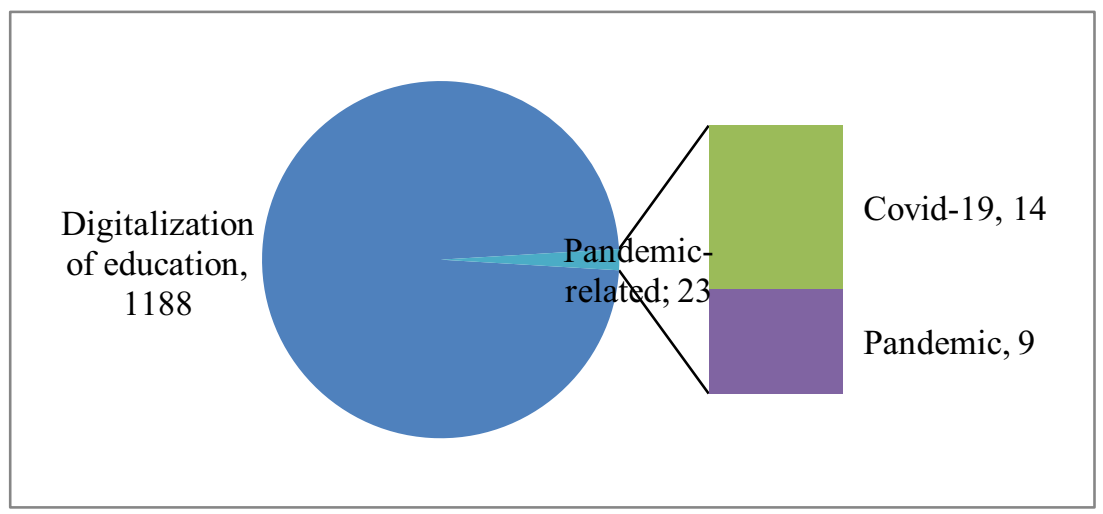

Fig. 6. Proportion of Publications with Pandemic-related Key Words (of the Total Number of 2020dated Publications with the Key Word "Digitisation" under the Section "Public Education. Pedagogics"), Source: the authors.

While "digitisation" is widely found among the key words in the papers on education published since the beginning of the pandemic 2020, the number of contributions containing a combination of "digitisation" and any pandemic-related key words is negligibly small. These were basically the items published in the conference proceedings. Among the issues of frequent concern was the use of digital education techniques as well as the case-studies of "force majeure" distance learning development. The authors tend to share their experience and perspectives of deploying digital strategies. Pandemic-specific measures promoting rapid transformation of academic and learning experiences and their potential for mitigating the shock of sudden full-fledged digitisation are being discussed in a variety of contexts.

\section{Conclusion}

The bulk of data collected from public discussions and papers indexed in the Russian Science Citation database revealed a gap between a vast number of materials issued as an 
immediate response to the pandemic-triggered shift of education into digital sphere and scarcity of academic research publications on the matter. The findings have evidenced a lively concern about the processes launched due to the "shock" digitisation of the field. Teaching staff interviews, questionnaires and experts' opinions highlighted diversity and urgency of challenges faced by the system of Russian education. Among the most vital are issues of digital capacities, demand for technical and methodological support, and lack of balanced and comprehensive approach to structuring teachers' and learners' workload. These challenges, however, seem unexplored and under conceptualized as far as the scope of the research papers is concerned. Despite the fact that the problems tend to be quickly spotted and outlined by practitioners, they hardly gain due consideration in terms of indepth research. The fact can be partly explained by the time needed for publishing research findings, especially if pre-planned nature of publication waiting lists is taken into account. Another explanation may lie behind the hectic character or current teaching routine, which can deprive educationalists of time and energy for scientific reflections.

\section{References}

1. Decree of the President of the Russian Federation dated March 25, 2020 No. 206 On the announcement of non-working days in the Russian Federation from March 30, 2020 to April 3 (2020)

2. Quarantine due to coronavirus in Russia: when was it introduced and will it end soon? (2020) https://coronavirus-covid2019.ru/karantin-v-rossii/

3. Passport of the federal project "Digital educational environment". Appendix to the minutes of the meeting of the project committee for the national project "Education" dated December 7, 2018 No. 3. (2018)

4. University 2035: instruction for use (2019)

5. Information Bureau. National Technological Initiative (2020)

6. CovidEd: how education went online due to the pandemic (2020) https://incrussia.ru/specials/covided/

7. Decree "On the national development goals of the Russian Federation for the period of up to 2030” dated July 21 (2020)

8. G.L. Tulchinsky, Russian Journal of Philosophical Sciences 6, 121-136 (2017)

9. S.D. Karakozov, A.Yu. Uvarov, Problems of Modern Education 2, 7-19 (2016)

10. A.M. Magomedov, Pedagogy and Education 2, 134 - 142 (2019)

11. E.V. Ustyuzhanina, S.G. Evsyukov, Vestnik of the Russian Plekhanov University of Economics 1(97), 3-12 (2018)

12. E.A. Dyakova, G.G. Sechkareva, Bulletin of Armavir State Pedagogical University 2, 24-36 (2019)

13. T.V. Nikulina, E.B. Starichenko, Pedagogical Education in Russia 8, 107-139 (2018)

14. N.P. Tabachuk, International Journal of Economics and Education 2(4), 90-94 (2016)

15. N.G. Khramtsova, T.Yu. Mayboroda, Perspectives of Science and Education 1(37), 8093 (2019)

16. A.V. Dmitrova, Azimuth of Scientific Research: Pedagogy and Psychology 9(1), 111$114(2020)$

17. V.A. Sukhomlin, E.V. Zubareva, A.V. Yakushin, Modern Information Technologies and IT-Education 13(2), 146-152 (2017) 
18. O.P. Chigisheva, The world of Academia: culture, education 9, 69-74 (2019)

19. G.U. Soldatova, O.I. Teslavskaya, Academic Bulletin of the Academy of Social Governance 3(25), 51-58 (2017)

20. M.V. Firsov, A.S. Sarychev, Y.V. Shimanovskaya, et al., Academic Journal of Interdisciplinary Studies 8(2), 96-101 (2019) doi: 10.2478/ajis-2019-0021

21. O.A. Anikeeva, V.V. Sizikova, T.E. Demidova, et al., Eurasia Journal of Mathematics, Science and Technology Education 15(11) (2019) doi: 10.29333/ejmste/109504

22. N.V. Dneprovskaya, Statistics and Economics 15(4), 16-28 (2018)

23. A.G. Savina, Education and Science without Borders: Basic and Applied Research 6, 208-211 (2017)

24. A.V. Dmitrova, O.P. Chigisheva, Yu.S. Timoshenko, International Journal of Economics and Education 5(3), 5-22 (2019)

25. M.R. Safiullin, E.M. Akhmetshin, International Journal of Engineering and Advanced Technology 9(1), 7387-7390 (2019) doi: 10.35940/ijeat.A3097.109119

26. E. Soltovets, O. Chigisheva, A. Dmitrova, Eurasia Journal of Mathematics, Science and Technology Education 16(4), em1839 (2020)

27. E. Plotnikova, IOP Conference Series: Materials Science and Engineering 497(1), 012047 (2019)

28. M. Tselykh, International Journal of Media and Information Literacy 4(2), 60-65 (2019)

29. E. Soltovets, O. Chigisheva, D. Dubover, Dilemas contemporaneos-educacion politica y valores 6(3), 50 (2019)

30. I.V. Robert, Professional education. Capital 3, 16-26 (2019)

31. V.I. Blinov, Professional education. Capital 3, 27-32 (2019)

32. I.Yu. Tarkhanova, Yaroslavl Pedagogical Bulletin 2(107), 45-52 (2019)

33. A.A. Tertychny, Bulletin of Moscow University. Series 10. "Journalism" 6, 46-69 (2016)

34. L. Cohen, L. Manion, K. Morrison, Research methods in education (Oxon, Routledge, 2007)

35. Teachers expressed their opinion about the forced transition of the educational process to online (2020) https://minobrnauki.gov.ru/ru/press-center/card/?id_4=2603

36. D. Saprykina, A. Volohovich (2020) https://www.eseur.ru/Files/file12216.pdf

37. LIVE: "Interception" plan: how to organize the continuity of "distance" education? Experience of the Ivanovo region (2020) https://ntinews.ru/news/unti/live-planperekhvat-kak-organizovat-preemstvennost-obrazovaniya-na-udalenke-opytivanovskoy-oblasti.html

38. LIVE: "Reconnaissance in force": designing online classes in the conditions of "distant" force majeure (2020) https://ntinews.ru/news/unti/live-razvedka-boemproektirovanie-onlayn-zanyatiy-v-usloviyakh-distantsionnogo-fors-mazhora-.html

39. LIVE: "Digital tests": how to carry out validation at the end of the academic year (2020) https://ntinews.ru/news/unti/live-ispytaniya-tsifroy-kak-provodit-attestatsiyupo-itogam-uchebnogo-goda.html

40. LIVE: "Course - on online": creating online courses as an opportunity to overcome the limitations of "distance" teaching (2020) https://ntinews.ru/news/unti/live-kurs-naonlayn-sozdanie-onlayn-kursov-kak-vozmozhnost-preodolet-ogranicheniyaprepodavaniya-na-.html 
41. K. Kolesnikova, Russian Gazette (2020) https://rg.ru/2020/04/13/opros-shkolniki-naudalenke-stali-bolshe-ustavat.html 